\title{
Correction to: Exchange Bias Effect in FeCo Nanoparticles
}

\author{
Pimsiri Potpattanapol ${ }^{1} \cdot$ I. Ming Tang ${ }^{2} \cdot$ Wuttichai Somyanonthanakun $^{1} \cdot$ Sirikanjana Thongmee $^{1}$
}

Published online: 4 December 2017

(c) Springer Science+Business Media, LLC, part of Springer Nature 2017

Correction to: J Supercond Nov Magn (2017)

https://doi.org/10.1007/s10948-017-4389-6

In the original publication of the article, the authors forgot to acknowledge the financial support from The Graduate School Kasetsart University. The correct Acknowledgement is shown below:

Acknowledgement In this work, we would like to thank Professor Ding Jun for use of the equipment (Superconductor Quantum Interference Vibrating Sample Magnetometer, SQUID, Quantum Design, MPMS 3). Moreover, we also are grateful for the financial support from The Graduate School Kasetsart University.

The authors regret the oversight.

The online version of the original article can be found at https://doi.org/10.1007/s10948-017-4389-6.

Sirikanjana Thongmee

fscisjn@ku.ac.th

1 Department of Physics, Faculty of Science,

Kasetsart University, Bangkok, 10900, Thailand

2 Computional and Applied Science for Smart Innovation

Cluster (CLASSIC), Faculty of Science, King Mongkut's

University of Technology Thonburi, Bangkok, 10140,

Thailand 